\title{
Assessing precipitation elasticity of streamflow based on the strength of the precipitation-streamflow relationship
}

\author{
$\underline{\text { Guobin Fu }}^{\text {a }}$, F.H.S. Chiew ${ }^{b}$, S.P. Charles ${ }^{a}$ and F. Mpelasoka ${ }^{b}$ \\ ${ }^{a}$ CSIRO Land and Water, Private Bag 5, Wembley, Western Australia; ${ }^{b}$ CSIRO Land and Water, GPO Box \\ 1666, Canberra, Australian Capital Territory \\ Email: Guobin.Fu@,csiro.au
}

\begin{abstract}
Water resource management increasingly seeks to incorporate the impacts of global climate change in the planning of future water supplies. Studies across numerous regions have documented the sensitivity of streamflow to climate change using the precipitation elasticity of streamflow, defined as the proportional change in streamflow to a change in precipitation. This study shows that calculating precipitation elasticity of streamflow without first assessing the strength of the precipitation-streamflow relationship can produce misleading and unrealistic results. For example, the Spokane river basin precipitation elasticity of streamflow is 0.90 by using annual precipitation and streamflow accumulated on a January-December calendar year basis. This indicates that a $10 \%$ change in annual precipitation would produce an annual streamflow change of 9.0\%. However, using water year (Oct-Sep, in this case) precipitation and streamflow data gives an elasticity of 1.65 , indicating a $10 \%$ change in annual precipitation would result in a $16.5 \%$ change in annual streamflow. Further analysis shows that the water year data has a much stronger precipitation-streamflow relationship $\left(\mathrm{R}^{2}=0.72\right)$ compared with the calendar year data $\left(\mathrm{R}^{2}=0.23\right)$. From this we infer that the precipitation elasticity of streamflow should be calculated using the seasonality that produces the strongest precipitation-streamflow relationship, as the precipitation elasticity of streamflow is sensitive to the strength of the precipitation-streamflow relationship. A useful practice is to use water year data series - with annual cycles starting from the beginning of the dry season or from just before the snowmelt period.
\end{abstract}

The results of the temporal variations of precipitation elasticity of streamflow for 30 and 50 year blocks indicate that 50 -yr-block time series generate less temporal variation, as expected given the longer time period used. These results have implications for the use of elasticity as a rule of thumb under changing climate and climate change and variability impact studies. It can be argued that it is better to use as long a record as possible to estimate elasticity as this captures the range of observed variability. However, with potential climate change and variability, there may be good reason to use only the most recent record (e.g., the most recent 30-50 years) to estimate the elasticity, or use dry or wet periods that are similar to future projections to quantify the climatic change impacts on streamflow.

The relationships between the elasticity values and annual rainfall, annual streamflow, and the runoff coefficient (ratio of annual streamflow to annual precipitation) for the Murray-Darling Basin indicate that the elasticity values are generally negatively correlated to these streamflow and runoff coefficient, i.e., a low flow period in general results in a larger elasticity value. Moreover, the relationship between elasticity and the runoff coefficient is stronger than that between elasticity and rainfall, with correlation coefficients of 0.423 and 0.089 respectively. The relationship between elasticity and streamflow is in-between at -0.260 . This implies that annual rainfall is not the only driving force causing larger elasticities in recent years. These research results can be used to guide the application of elasticity methods to quantify hydrological responses to climatic change that inform long-term water management strategies.

Keywords: Precipitation Elasticity of Streamflow, Precipitation-Streamflow Relationship, Spokane River Basin, Murray-Darling Basin, Yellow River Basin 
Fu et al., Precipitation elasticity of streamflow based on the precipitation-streamflow relationship

\section{INTRODUCTION}

Numerous studies for basins across the world have documented the sensitivity of streamflow to climate change by estimating the precipitation elasticity of streamflow. The concept of elasticity, originating in economics, was introduced by Schaake (1990) for evaluating the sensitivity of streamflow to changes in climate as:

$$
\varepsilon_{p}(P, Q)=\frac{d Q / Q}{d P / P}=\frac{d Q}{d P} \frac{P}{Q}
$$

This relates how a change in precipitation of $d P$ will produce a change on streamflow $d Q$. In percentage terms, the percentage change in streamflow will be $\varepsilon_{p}$ times the percentage change in precipitation (Schaake, 1990). Dooge (1992) and Dooge et al. (1999) termed this a 'sensitivity factor' and Kuhnel et al. (1991) termed it a 'magnification factor'.

One difficulty with estimation of elasticity is that it is often estimated from a hydrological model and the mathematical form of the hydrological model is always an approximation with validation remaining a fundamental challenge (Sankarasubramanian et al., 2001). In order to solve this problem, Sankarasubramanian et al. (2001) introduced a specific case of (1) at the mean value of the climatic variable:

$$
\varepsilon_{p}\left(\mu_{p}, \mu_{Q}\right)=\left.\frac{d Q}{d P}\right|_{P=\mu_{P}} \frac{\mu_{P}}{\mu_{Q}}
$$

Where $\mu_{P}$ and $\mu_{Q}$ denote mean values of precipitation and streamflow. Sankarasubramanian et al. (2001) used this definition of $\varepsilon_{p}$ as the metric for comparing the climate response of river basins.

Sankarasubramanian et al. (2001) further verified that the non-parametric estimator:

$$
e_{P}=\operatorname{median}\left(\frac{Q_{t}-\bar{Q}}{P_{t}-\bar{P}} \frac{\bar{P}}{\bar{Q}}\right)
$$

is a robust estimator of the precipitation elasticity of streamflow for a wide class of hydrological models, independent of the form of the hydrological model. Several studies have used (3) to investigate the simulated impacts of climate change on annual streamflow. For example, Sankarasubramanian and Vogel (2003) used it to document the precipitation elasticity of streamflow for 1337 basins in the USA showing that a $1 \%$ change in precipitation results in a $1.5-2.5 \%$ change in basin runoff, depending upon the degree of buffering by storage processes and other factors. Fu et al. (2007a) have extended (3) into a two parameter index, i.e., climate elasticity of streamflow as a function of both precipitation and temperature, and Zheng et al. (2009) have proposed an alternative nonparametric estimator of climate elasticity $\left(\boldsymbol{\xi}_{\mathrm{p}}\right)$ to overcome the problem of (3) being compromised for small sample sizes.

Such metrics should not be applied blindly, however, as they need to be calculated correctly and interpreted meaningfully. The purpose of this study is to show that naive application of precipitation elasticity of streamflow (3), without adequately accounting for the precipitation-streamflow relationship, produces misleading and unrealistic results. Our results provide a reference or guideline for application of elasticity methods to quantify the hydrological responses to climatic change that inform long-term water management strategies.

\section{MATERIALS AND METHODS}

\subsection{Elasticity and precipitation-streamflow correlation coefficient}

Equation (3) uses annual averages to compute the precipitation elasticity of streamflow. However, the time periods used to accumulate the annual average values may have significant impacts on the computed results, as well as precipitation-streamflow correlation coefficients. To explore the effects of precipitationstreamflow relationships on the elasticity values, annual averages of precipitation and streamflow were computed for all 12-month periods, i.e., January-December, February-January, March-February, etc. (Najjar, 1999; Fu et al., 2007b). The elasticity values and precipitation-streamflow correlation coefficients were then computed for those 12 time series. The time series having the strongest precipitation-streamflow relationship is inferred to produce a more appropriate elasticity value estimate, which is then used as a bench mark to assess the other elasticity values. 
Fu et al., Precipitation elasticity of streamflow based on the precipitation-streamflow relationship

\subsection{Study Regions}

Three contrasting basins have been used in this study to explore precipitation-streamflow relationship effects on the precipitation elasticity of streamflow: the Spokane River basin in the north-west USA, the Yellow River Basin in China, and the Murray-Darling basin in south-east Australia. Since these three large basins are heavily regulated, the estimated naturalized flows are used instead of observed ones to explore the precipitation elasticity of streamflow and precipitation-streamflow relationship

The Spokane River basin has a catchment area of $17,200 \mathrm{~km}^{2}$ and is located in eastern Washington and northern Idaho, USA. It is a tributary to the Columbia River above Grand Coulee Dam and provides a vital contribution to the quality of life in Spokane and Coeur d'Alene cities, offering riverfront trails and parks, a prized trout fishery, whitewater recreation, and dramatic natural scenery. However, the river was ranked No. 6 on the most endangered rivers in America list in 2005 by American Rivers and its Partners (American Rivers, 2005) due to "too little water, too much pollution, and an uncertain future." Based on the estimates of Fu et al. (2007b), the long-term (1917-2001) water year (October to September) average annual precipitation for the Spokane River Basin is $797 \mathrm{~mm}$. About $55.3 \%$ of precipitation, or $441 \mathrm{~mm}$, becomes streamflow sometime during the water year, a runoff coefficient of 0.553 .

The Yellow River is the $6^{\text {th }}$ longest river in the world and $2^{\text {nd }}$ longest river in China. The catchment area is about 794,712 $\mathrm{km}^{2}$ if the Erdos inner flow area is included (Fu et al., 2004). The average annual precipitation for 1957-1997 was $455.8 \mathrm{~mm}$ for the entire basin, based on the 44 stations of Fu et al $(2007 \mathrm{c})$. The average annual streamflow at Hua-Yuan-Kou station is $5.747 \times 10^{10} \mathrm{~m}^{3}$, a runoff depth of $78.7 \mathrm{~mm}$. The runoff coefficient is thus only 0.173 (Fu et al., 2007c). With population growth and regional economic development, the observed streamflow of the Yellow River has decreased significantly during the last 50 years. In the drought year 1997, the river no-flow period lasted 227 days at Li-Jin station, and for 330 days there was no water discharged to the sea.

The Murray-Darling Basin (MDB), with a catchment area of more than one million square kilometres, is Australia's most important agricultural region, producing one-third of Australia's total output for natural resource-based industries, worth approximately \$14 billion per year (Cai and Cowan 2008). Precipitation and streamflow have experienced significant decreasing trends in recent years, of immense concern to MDB water managers and irrigators (Cai and Cowan 2008, Potter et al., 2010, Yu et al., 2010). The long-term (1900-2006) annual rainfall for MDB is about 476mm and annual streamflow is about $10980 \mathrm{GL}$ ( 1 GL = $10^{9}$ litres) for the same period. However, the MDB streamflow has historically been subject to both extreme floods and droughts. For example, during the current drought (2000-2007) the average annual inflow has been $4150 \mathrm{GL} \mathrm{yr}^{-1}$. In 2006-2007, the 12-month streamflow reached a historical low of $770 \mathrm{GL} \mathrm{yr}^{-1}$ to $\mathrm{March}^{-}$ 2007 (Cai and Cowan 2008). In contrast, the annual inflow in 1956 was about five times as large as the longterm average.

\section{RESULTS AND DISCUSSION}

\subsection{Streamflow-precipitation relationship and elasticity}

Table 1 summarises the streamflowprecipitation relationship (using the coefficient of determinations of annual time-series) and corresponding precipitation elasticity of streamflow values for the 12 time series for the three study basins. This clearly indicates that the time periods used to accumulate the annual average
Table 1. The coefficient of determinations and precipitation elasticity of streamflow from 12 times series for three study basins

\begin{tabular}{|c|c|c|c|c|c|c|}
\hline \multirow{2}{*}{} & \multicolumn{2}{|c|}{$\mathrm{MDB}(1950-2006)$} & \multicolumn{2}{c|}{ Spokane(1940-2000) } & \multicolumn{2}{c|}{ Yellow (1960-2000) } \\
\cline { 2 - 7 } & $\mathrm{R}^{2}$ & Elasticity & $\mathrm{R}^{2}$ & Elasticity & $\mathrm{R}^{2}$ & Elasticity \\
\hline Jan-Dec & 0.53 & 1.92 & 0.23 & 0.90 & 0.59 & 1.54 \\
\hline Feb-Jan & 0.43 & 1.78 & 0.18 & 0.51 & 0.61 & 1.61 \\
\hline Mar-Feb & 0.44 & 2.12 & 0.17 & 0.41 & 0.61 & 1.64 \\
\hline Apr-Mar & 0.35 & 2.00 & 0.20 & 0.69 & 0.63 & 1.61 \\
\hline May-Apr & 0.29 & 2.19 & 0.43 & 0.84 & $\mathbf{0 . 6 8}$ & $\mathbf{1 . 7 6}$ \\
\hline Jun-May & 0.25 & 2.18 & 0.65 & 1.38 & 0.63 & 1.51 \\
\hline Jul-Jun & 0.30 & 1.89 & $\mathbf{0 . 7 2}$ & $\mathbf{1 . 3 8}$ & 0.65 & 1.63 \\
\hline Aug-Jul & 0.35 & 1.19 & 0.71 & 1.57 & 0.49 & 1.88 \\
\hline Sep-Aug & 0.45 & 1.67 & $\mathbf{0 . 7 2}$ & $\mathbf{1 . 5 4}$ & 0.26 & 0.69 \\
\hline Oct-Sep & 0.52 & 2.14 & $\mathbf{0 . 7 2}$ & $\mathbf{1 . 6 5}$ & 0.32 & 0.51 \\
\hline Nov-Oct & $\mathbf{0 . 5 6}$ & $\mathbf{2 . 1 4}$ & 0.69 & 1.51 & 0.43 & 1.29 \\
\hline Dec-Jan & 0.52 & 1.80 & 0.44 & 1.38 & 0.56 & 1.47 \\
\hline
\end{tabular}


values have significant impacts on the streamflow-precipitation relationship and their corresponding elasticity values. If the time series having the strongest precipitation-streamflow relationship, i.e. highest coefficient of determinations, is inferred as producing a more appropriate elasticity value, then the precipitation elasticity values of streamflow are 2.14, 1.38-1.65, and 1.76, for the MDB, the Spokane river basin, and the Yellow river basin, respectively. This implies that for every $10 \%$ change in precipitation, the streamflow would change on-average $21.4 \%, 13.8-16.5 \%$, and $17.6 \%$ for these three basins respectively.

This conclusion is shown clearly in Figure 1 for the Spokane River basin streamflow-precipitation relationships for calendar and water year (Oct-Sep) time series respectively. Since time series of water year produces a much stronger streamflow-precipitation relationship (Figure 1b), it is reasonable to assume that it results in a more appropriate precipitation elasticity of streamflow, which is much higher than that obtained from calendar year time series.

An inappropriate accumulation of annual values of streamflow and precipitation can either overestimate or underestimate elasticity values. In most cases it results in underestimation, especially for the Spokane River basin (Table 1). There are differences between the three study basins - using calendar year precipitation and streamflow data results in a small difference in elasticity values for the MDB (1.92 vs 2.14) and the Yellow river basin $(1.54$ vs 1.76), but a larger difference for the Spokane River basin (0.90 vs 1.38-1.65) (Table 1). The Spokane River basin represents basins that are winter dominated hydrologically, so this implies that mountain and high-latitude catchments, where winter snow accumulation and spring snowmelt process are critical for runoff generation, can have elasticities that are more
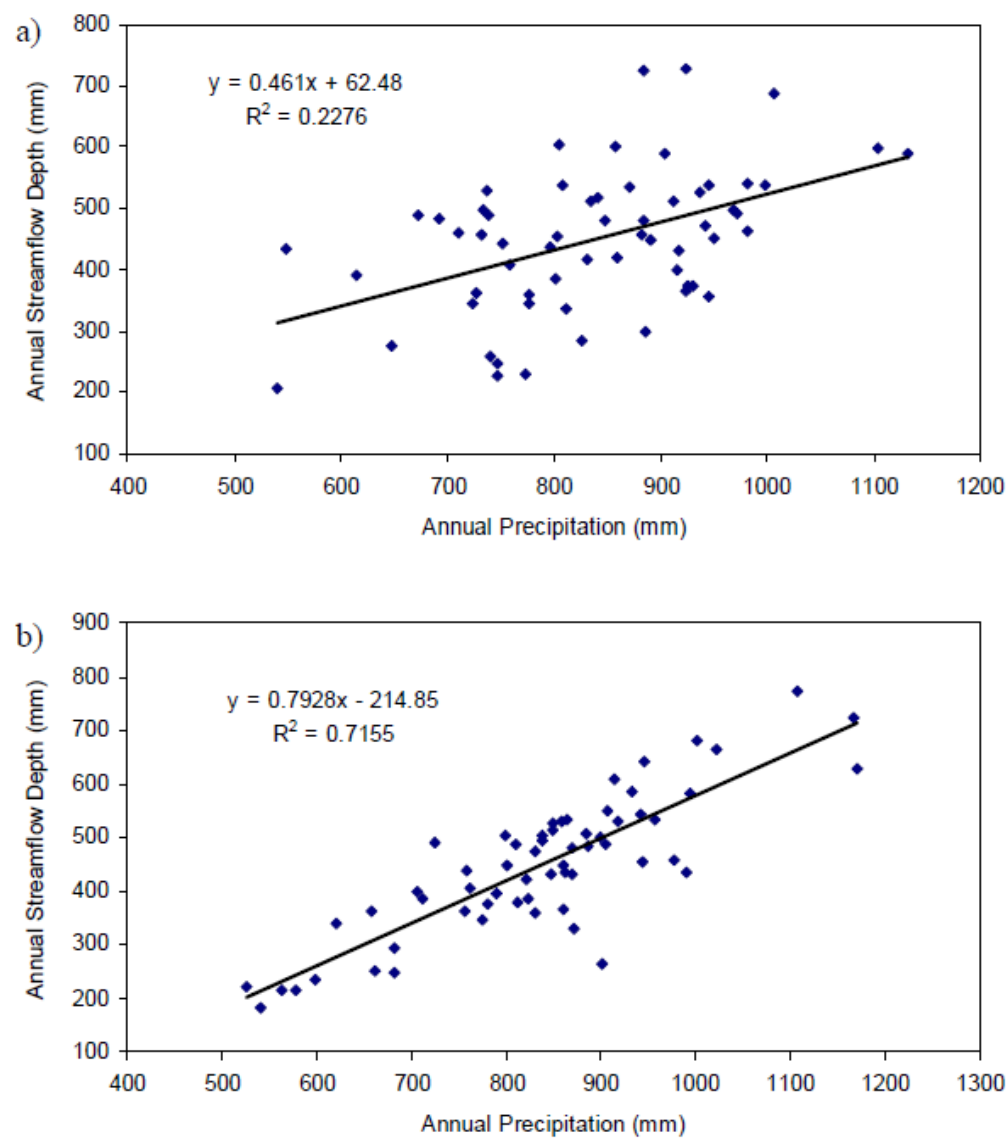

Figure 1 Spokane River basin streamflow-precipitation relationships for (a) calendar and (b) water year (Oct-Sep) time series sensitive to the time periods to accumulate annual values, as well as to the precipitation-streamflow relationship.

The time series resulting in the strongest streamflow-precipitation relationship varies from region to region: it is Nov-Oct for the MDB, May-Apr for the Yellow river basin, and for the Spokane River basin three time series produce the same correlation coefficients. When this happens other factors such as temperature should be taken into account. For example, Fu et al. (2007b) have examined how temperature improves the precipitation-streamflow correlation for the Spokane river basin concluding that the standard water year gives the largest improvement. This could be extended to a general principal that the water year should be used since it best represents the general hydrological processes.

In summary, the precipitation elasticity of streamflow given by (3) needs to be calculated by considering the strength of the precipitation-streamflow relationship. A useful practice is to use water year data series - with annual cycles starting from the beginning of the dry season or from just before the snowmelt period. 
Fu et al., Precipitation elasticity of streamflow based on the precipitation-streamflow relationship

\subsection{Temporal variations of precipitation elasticity of streamflow}

We now turn our investigation to whether the precipitation elasticity of streamflow is robust. For the MDB and Spokane we use 30 and 50 year blocks to compute the precipitation elasticity of streamflow, i.e., for the MDB the elasticity values of 1900-1929, 1901-1903 ... ... 1977-2006 for 30 year blocks and 1900-1949, 1901-1959, ... ...1957-2006 for 50 year blocks. The Yellow river basin has only 40 year data, so it has not been used for this study.

The results have implications for the use of elasticity as a rule of thumb under changing climate and climate change and variability impact studies (Figure 2). It can be argued that it is better to use as long a record as possible to estimate elasticity as this captures the range of observed variability. However, with potential climate change and variability, there may be good reason to use only the most recent record (e.g., the most recent $30-50$ years) to estimate the elasticity, or use dry or wet periods that are similar to future projections to quantify the climatic change impacts on streamflow.

The relationships between the elasticity values and annual

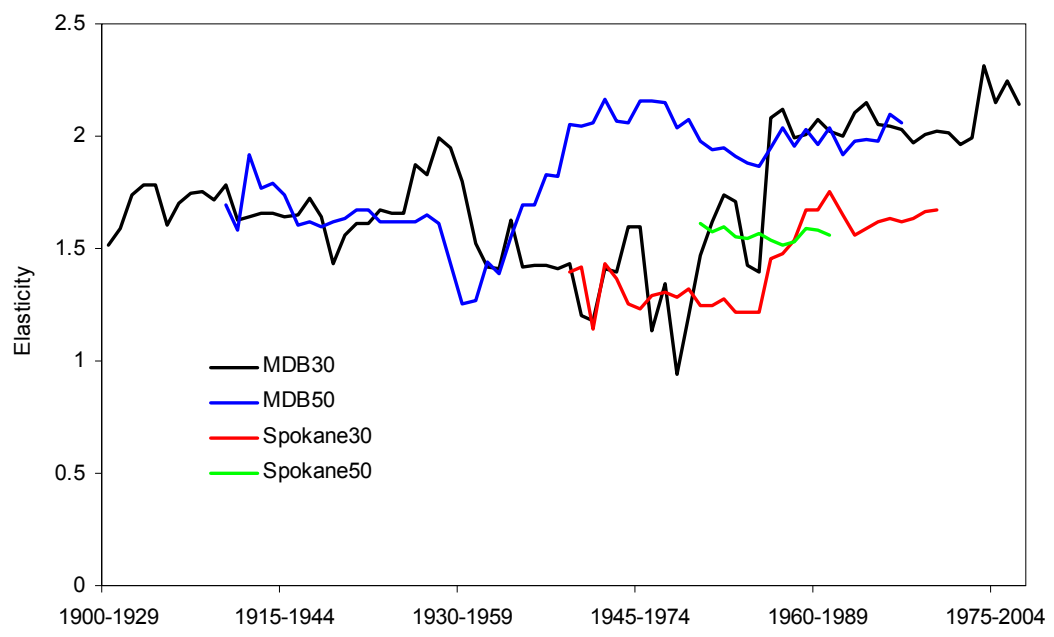

Figure 2 MDB and Spokane river basin time series of elasticity values for every 30 and 50 year block

rainfall, annual streamflow, and the runoff coefficient (ratio of annual streamflow to annual precipitation) for the MDB are further investigated to explore the responses of elasticity to dry/wet periods. The results indicate that while the elasticity values are generally negatively correlated to streamflow and runoff coefficient, this is not necessarily the case for precipitation. Thus a low streamflow or runoff coefficient period in general results in a larger elasticity value (Figure 3), but a period of low precipitation by itself does not result in a larger elasticity value.

Moreover, the relationship between elasticity and the runoff coefficient is stronger than that between elasticity and rainfall (Figure $3)$, with correlation coefficients of 0.423 and 0.089 respectively. The relationship between elasticity and streamflow is in-between at 0.260 . This implies that annual rainfall is not the only driving force causing larger elasticities in

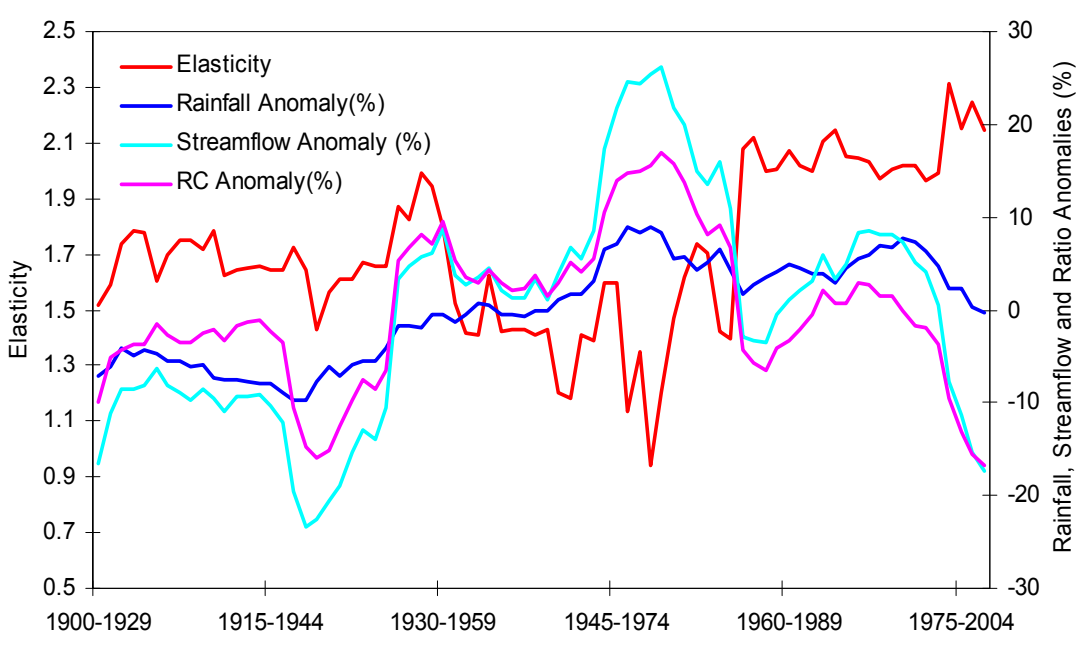

Figure 3 MDB 30-year-mean time series of elasticity values, rainfall anomaly, streamflow anomaly, and the runoff coefficient anomaly 
Fu et al., Precipitation elasticity of streamflow based on the precipitation-streamflow relationship

recent years. This may be related to recent regional climate changes, which have not only increased temperature and actual evapotranspiration, but are also potentially associated with changes in precipitation characteristics that modify hydrological processes and streamflow generation (Potter et al., 2009; 2010, Yu et al., 2010). This is the subject of on-going research.

\section{CONCLUSIONS}

The index of the precipitation elasticity of streamflow is a useful and easy-to-use tool to quantify streamflow sensitivity to precipitation change. However, the results of this study indicate that the time periods used to accumulate annual values are critical for computing this index due to varying streamflow-precipitation relationships. The time series having the strongest precipitation-streamflow relationship should be used to compute elasticity, and a useful practice is to use water year data series - with annual cycles starting from the dry season or from just before the snowmelt period. The length of time series used also critically influences the estimation of the precipitation elasticity of streamflow. It is recommended to use as long a record as possible to estimate elasticity in order to capture the full range of observed variability. However, with potential climate change and variability, there may be a good reason to use the most recent record (e.g., the most recent 30-50 years) to estimate elasticity, or dry or wet periods that are similar to future projections to quantify the climatic change impacts on streamflow. These research results can be used as a reference when applying the elasticity method to quantify general rule-of-thumb hydrological responses to climatic change to inform long-term water management strategies.

\section{REFERENCES}

American Rivers (2005), http://www.waterplanet.ws/ endangeredriver/\#6

Cai, W. and Cowan, T. (2008), Evidence of impacts from rising temperature on inflows to the MurrayDarling Basin. Geophys. Res. Lett., 35, L07701, doi:10.1029/2008GL033390.

Chiew, F.H.S. (2006), Estimation of rainfall elasticity of streamflow in Australia. Hydrological Sciences Journal, 51, 613-625.

Dooge, J. C. I. (1992), Sensitivity of runoff to climate change: A Hortonian approach, Bull. Am. Meteorol. Soc., 73, 2013-2024.

Dooge, J. C. I., M. Bruen, and B. Parmentier (1999), A simple model for estimating the sensitivity of runoff to long-term changes in precipitation without a change in vegetation, Adv. Water Resour., 23, 153-163.

Fu, G.B., Chen, S.L., Liu, C.M., and Shepard D. (2004), Hydro-climatic trends of the Yellow River basin for the last 50 years. Clim. Change, 65, 149-178.

Fu, G.B., Barber, M. E., and Chen S.L. (2007a), The impacts of climate change on regional hydrological regimes in the Spokane River watershed. J. Hydrol. Eng., 12, 452-461.

Fu, G.B., Charles, S. P., and Chiew, F. H. S. (2007b), A two-parameter climate elasticity of streamflow index to assess climate change effects on annual streamflow. Water Resour. Res., 43, W11419, doi:10.1029/2007WR005890.

Fu, G.B., Charles, S. P., Viney, N. R., Chen, S.L., and Wu J. Q. (2007c), Impacts of climate variability on streamflow in the Yellow River, Hydrol. Processes, 21, 3431-3439, doi:10.1002/hyp.6574.

Kuhnel, V., J. C. I. Dooge, J. P. J. O’Kane, and R. J. Romanowicz (1991), Partial analysis applied to scale problems in surface moisture fluxes, Surv. Geophys., 12, 221-247.

Najjar, R.G. (1999), The water balance of the Susquehanna Basin and its response to climatic change. $J$. Hydrol., 219, 7-19.

Potter, N.J, and Chiew F. H. S. (2009), Statistical characterisation and attribution of recent precipitation and runoff in the Murray-Darling Basin, MODSIM 2009

Potter N. J., Chiew, F. H. S. \& Frost, A. J. (2010), An assessment of the severity of recent reductions in rainfall and runoff in the Murray-Darling Basin. J. Hydrol. 381, 52-64.

Sankarasubramanian, A., Vogel, R. M., and Limbrunner J. F. (2001), Climate elasticity of streamflow in the United States. Water Resour. Res., 37, 1771- 1781.

Sankarasubramanian A., and R. M. Vogel (2003), Hydroclimatology of the continental United States, Geophys. Res. Lett., 30(7), 1363, doi:10.1029/2002GL015937.

Schaake, J. C. (1990), From climate to flow, in Climate Change and U.S. Water Resources, edited by P. E. Waggoner, chap. 8, pp. 177-206, John Wiley, New York.

Yu, J. J., Fu, G. B., Cai, W. \& Cowan, T. (2010), Impacts of precipitation and temperature changes on annual streamflow in the Murray-Darling Basin. Water Int. 35, 313-323.

Zheng, H., L. Zhang, R. Zhu, C. Liu, Y. Sato, and Y. Fukushima (2009), Responses of streamflow to climate and land surface change in the headwaters of the Yellow River Basin, Water Resour. Res., 45, W00A19, doi:10.1029/2007WR006665. 